\title{
ANALISA PERAN FRONT DESK AGENT DALAM PEMBENTUKAN CITRA POSITIF DI VILA BALI ASRI SEMINYAK- BALI
}

\author{
Gusti Ayu Agustina Riski \\ Akademi Komunitas Manajemen Perhotelan Indonesia \\ agustina.riski@triatma-mapindo.ac.id
}

\begin{abstract}
Abstrak
Sebagai departemen yang operasionalnya di Front Office, Front Desk Agent memiliki peran penting sebagai first and last impression dari sebuah Hotel, sehingga perannya sangat pentin dalam pembentukan citra yang positif terhadap hotel. Implementasinya adalah dengan memberikan pelayanan tamu dengan penuh keramah tamahan, koordinasi dengan antar departemen, pelayanan penjualan kamar, pelayanan keluhan tamu, dan lain sebagainya. Studi kasus pada penelitian ini adalah mengamati peran Front Desk Agent di Vila Bali Asri dalam pembentukan citra positif terhadap Vila tersebut. Pentingnya peran tersebut ditunjukkan dalam memberikan First and last Impression yang baik dalam memberi layanan yang efektif dan efisien agar tamu merasa nyaman dan puas baik sebelum menginap, selama menginap, sampai tamu meninggalkan hotel. Untuk menunjang Peran Front Desk Agent dalam memberikan pelayanan, Front Desk Agent harus mengacu pada lima dimensi kualitas layanan yaitu Reliability (keandalan), Responsiveness (cepat tanggap), Assurance (jaminan), empathy (empati), tangible (berwujud). Metode penelitian yang digunakan adalah deskriptif, dengan menganalisa data primer dan sekunder melalui observasi langsung dan wawancara dengan pihak terkait di Vila Bali Asri Seminyak. Hasil dari penelitian ini adalah Peran Front Desk Agent sangat penting dalam pembentukan citra positif (Image builder) di Vila Bali Asri Seminyak Bali, dimana Front Desk Agent berperan dalam memberikan first and last impression yang baik dalam pelayanan tamu. Keberhasilan peran Front Desk Agent dalam pembentukan citra positif dapat diamati dari tingkat kepuasan pelanggan melalui guest review baik secara online maupun offline.
\end{abstract}

Keyword: front Desk Agent, Front Office Departemen, Citra Positif, dimensi kualitas pelayanan

\section{PENDAHULUAN}

Peran seorang Front Desk Agent di sebuah hotel yang utama adalah bagaimana membentuk pelayanan yang efektif dan efisien agar tamu merasa nyaman dan puas baik sebelum menginap (pre-arrival), selama menginap (during the stay), sampai tamu meninggalkan hotel (departure) dengan tidak menyampingkan peran lainnya sebagai bagian dari departemen Front Office agar dapat menciptakan pelayanan yang maksimal dan kesan yang positif mulai dari tamu datang sampai dengan tamu meninggalkan hotel (first and last impression). Sanjang (2016) berasumsi bahwa Front Office Departemen merupakan salah satu departemen hotel yang memiliki peran yang sangat penting, yang bisa dikatakan juga sebagai jantung dari hotel, karena menjadi pusat informasi bagi tamu dan departemen lain, dimana kualitas layanan yang diberikan akan berdampak pada penilaian tamu. Selain itu juga, pelayanan yang diberikan oleh karyawan Front Office Departemen sangat berpengaruh karena akan meninggalkan kesan bagi tamu. Febryani dan Puspasari 
(2017) berasumsi bahwa kinerja yang baik dari Departemen Front Office untuk memberikan kemudahan pada tamu mempunyai peranan yang besar dalam industri jasa seperti hotel. Seorang Resepsionis harus memahami dengan baik mengenai prosedur check in dan check out guna memperlancar aktivitas tamu agar tidak menunggu lama di lobi hotel saat melakukan check in dan check out dan memberikan kesan positif kepada tamu. Keberhasilan resepsionis dalam menangani proses check in merupakan langkah awal yang memiliki arti penting dalam membentuk citra tamu terhadap hotel, yang selanjutnya akan mempengaruhi kesan secara keseluruhan selama tamu menginap di hotel.

Mengingat keterbatasan Sumber Daya Manusia yang dimiliki maka seorang Front Desk Agent diharapkan berperan multifungsi selain sebagai resepsionis, juga sebagai reservasi, e-commerce, guest service agent, dan juga buttler serta diharapkan untuk multitasking dalam memberikan pelayanan dari sebelum tamu check in, kedatangan tamu, selama tamu menginap hingga tamu check out. Disitulah peranan Front Office sangat penting untuk memberikan pelayanan yang baik dan memuaskan tamu, sehingga membuat citra yang baik bagi Villa. Citra positif diperoleh dari berbagai kesan tamu selama tamu menginap (Guest Review) baik melalui online (tidak langsung) maupun melalui Guest Feedback Card yang selalu dibagikan sehari sebelum tamu check out. Diharapkan dengan meningkatnya citra positif dari Vilamaka akan bersinergi dengan peningkatan penjualan, serta loyalitas pelanggan.

Vila Bali Asri Seminyak merupakan sebuah Vila yang berada di kawasan Seminyak, tepatnya berada di Jl. Sari Dewi no 33 Seminyak, dan berada di bawah kepemilikan PT. Harmoni Bali. Vila Bali Asri memiliki dua cabang yaitu berada di Seminyak dan Batu Belig. Vila Bali Asri Seminyak beroperasi sejak tahun 2005 dan memiliki fasilitas berupa 11 unit Vila yang terdiri dari 2 unit Three Bedroom Villa, 4 unit Two Bedroom Villa, dan 4 Unit One Bedroom Villa), dan dilengkapi fasilitas gym dan spa. Sejak berdirinya di tahun 2005, kebanyakan pengunjung pada Vila Bali Asri ini merupakan tamu repeater, artinya tamu yang sudah pernah tinggal di Vila Bali Asri mendapatkan kepuasan selama tinggal, dan melakukan kunjungan kembali (re-visit). Kepuasan tamu merupakan tanggung jawab dari Vila Bali Asri sebagai pengelola (host) supaya dapat meningkatkan penjualan kamar dan fasilitas lainnya. Dalam hal ini khususnya departemen Front Office yang berperan dalam pelayanan kepada tamu sebelum tamu datang (pre-arrival) hingga keberangkatan (departured).

Adapun tujuan penelitian ini adalah untuk menganalisa peran Front Desk Agent dalam membentuk Citra Positif pada Vila Bali Asri.

\section{METODE}

Metode Penelitian Deskriptif digunakan penulis untuk menjelaskan dan menggambarkan peran Front Desk Agent dalam pembentukan citra di Vila Bali Asri.

\section{Sumber Data}

Data yang digunakan penelitian ini adalah data primer dan data sekunder. Data primer dalam penelitian ini berupa kata-kata, kalimat, atau pemaparan yang diperoleh dari subyek penelitian yaitu Front Desk Agent di Vila Bali Asri Seminyak. Data primer diperoleh melalui observasi dan wawancara dengan berbagai pihak terkait di Vila Bali Asri, yaitu General manager, Front Office staff, dan beberapa tamu. 
Sedangkan Data sekunder dalam penelitian ini diperoleh dari sumber tidak langsung, antara lain dokumentasi dan arsip- arsi yang mendukung hasl penelitian. Data sekunder diperoleh melalui studi literature dari buku buku terkait, jurnal, artikel terkait Peran Front Desk Agent dalam pembentukan citra positif di Vila Bali Asri Seminyak.

\section{Metode dan Teknik Pengumpulan Data}

Dalam penelitian ini pengumpulan data dilakukan dengan menggunakan metode observasi. Metode Observasi adalah pengumpulan data yang dilakukan dengan cara mengamati dan mencata secara sistematik gejala- gejala yang diselidiki (Rai, 201:52). Metode obsrvai digunakan untuk memperoleh data mengenai peranan Front Desk Agent dalam operasional Front Office dan terutama terhadap pembentukan citra positif di Vila Bali Asri Seminyak-Bali. Teknik Pengumpulan data yang digunakan dalam penelitian ini adalah teknik wawancara dan dokumentasi. Pihak-pihak terkait yang diwawancarai adalah pihak manajemen di Vila Bali Asri, Front Desk Agent, serta tamu yang sudah menginap di Vila Bali Asri Seminyak.

\section{Metode dan Teknik Analisa Data}

Teknik analisa yang digunakan untuk menganalisa data dalam penelitian ini adalah analisis deksriptif kualitatif. Analisa kualitatif merupakan suatu kegiatan analisis yang terdiri atas beberapa kegiatan yaitu komparasi data, verifikasi, dan penyajian data. Data disajikan dengan pemaparan kata untuk memberikan gambaran yang jelas tentang obyek yang diteliti dan permasalahan yang dibahas. Kemudian dilakukan komparasi data, penyajian data, dan penarikan simpulan secara berurutan sebagai rangkaian kegiatan analisis yang berlandaskan pada kajian pustaka, konsep, kerangka teori, dan metode analisis kualitatif.

\section{HASIL DAN PEMBAHASAN}

\section{Front Office}

Menurut Suarthana (1986: 27) Front Office merupakan bagian atau departemen yang bertanggungjawab dalam penjualan kamar hotel baik melalui pemesanan (reservation) seebelumnya maupun tanpa pemesanan, dilanjutkan dengan pendaftaran (registration) dan penunjukan kamar (room assignment) bagi tamu. Dimana Front Office adalah salah satu department di hotel secara operasional berhubungan langsung dengan tamu- tamu di hotel. Peran Penting Front Office bagi sebuah hotel antara lain sebagai berikut:

1) Merupakan pusat kegiatan hotel, bagian ini merupakan sebuah otak atau pusat dari kegiatan hotel, dari tempat inilah awal atau mulai dijalankannya peranan awal hubungan tamu dengan hotel, dari pada saat permulaan datang kemudian menginap hingga meninggalkan hotel

2) Para tamu mendapatkan pelayanan pada saat tiba, berada, dan pada waktu akan meninggalkan hotel.

3) Memegang peranan utama dipandang dari segi pemasukan atau penghasilan hotel. Pendapatan yang diperoleh dari penjualan kamar melebihi separuh dari pendapatan seluruh hotel, disamping presentase keuntungan dari penjualan kamar itu sendiri sangat tinggi.

4) Pembentuk citra hotel yang baik, sebagai kesan pertama pada saat tamu tiba, kesan selam tamu berada di hotel dan kesan terakhir pada saat tamu meninggalkan hotel. 
5) Pusat syaraf ataupun pusat nadi (nerve servis) dan pusat kegiatan dari suatu operasional hotel serta yang meliputi kegiatan di meja pendaftaran (reception counter desk), pemesanan kamar (room reservation), informasi (information), telepon dan pelayanan barang (uniformed service).

Sejalan dengan Suarthana, Richard Sihite (2000) mendefinisikan tujuan dari Front Office adalah sebagai berikut :

1. Meningkatkan tingkat hunian kamar serta pendapatan hotel dari tahun ke tahun

2. Meningkatkan jumlah tamu langganan

3. Memenuhi kebutuhan dan kepuasan tamu secara baik, tepat, dan cepat kepada tamu

4. Membentuk citra hotel yang positif, Front Office memiliki fungsi mewujudkan tujuan dari hotel

5. Fungsi tersebut dilakukan oleh petugas Front Office setiap hari, yaitu:

a) Menjual kamar, kegiatan yang dilakukan antara lain menerima pemesanan kamar, melakukan pendaftaran tamu, memblok kamar

b) Memberikan informasi tentang hotel

c) Mengkoordinasikan kepada bagian lain untuk memenuhi keinginan tamu

d) Melaporkan status kamar terkini

e) Mencatat, memeriksa pembayaran tamu serta menangani rekening tamu

f) Membuat laporan yang dibutuhkan oleh hotel
g) Memberikan pelayanan telekomunikasi untuk tamu
h) Memberikan peayanan barang bawaan tamu menyelesaikan keluhan tamu.
i) Menerima dan

Hadi (2014) berasumsi bahwa dalam sebuah hotel, Front Office merupakan bagian terpenting dalam sebuah operasional karena bertindak sebagai ujung tanduk dari seluruh bagian dan kegiatan yang ada di sebuah hotel, mulai dari pemesanan kamar, menjadi operator telephone, menangani tamu yang hendak check in maupun check out, sebagai sumber informasi, hingga sebagai tempat menerima permintaan tamu dan menangani keluhan tamu. Dan semua dilakukan berdasarkan prosedur yang sudah ditetapkan oleh manajemen hotel.

Menurut Wardoyo (1985) Organisasi Front Office akan dipengaruhi oleh kualifikasi besar kecilnya suatu hotel dan beban kerja yang menjadi tanggung jawab suatu departemen, jumlah kamar yang dimiliki, peralatan yang dimiliki, serta jumlah karyawan yang ada di Front Office. Pengorganisasian Front Office hotel bisa berbeda antara satu hotel dengan hotel lainnya tergantung pada klasifikasi dan kebijakan manajemen yang diterapkan. 
Bagan 1.

Struktur Organisasi pada Vila Bali Asri Seminyak

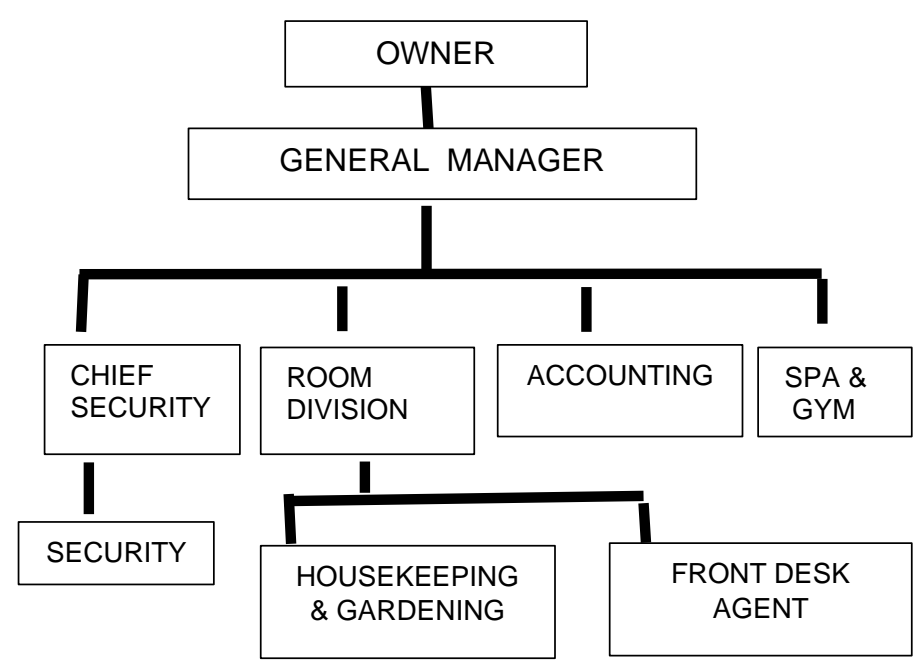

Sumber : Vila Bali Asri, 2018

Job Description di Vila Bali Asri dapat dideskripsikan pada tabel berikut ini

Tabel 1.

Peran dan Jobdes di Vila Bali Asri

\begin{tabular}{ll}
\hline \multicolumn{1}{c}{ Jabatan } & \multicolumn{2}{c}{ Deskripsi Tugas } \\
\hline Cooperate & merupakan sekumpulan \\
Owner & $\begin{array}{l}\text { investor yang menjadi } \\
\text { pemilik dari unit-unit di Vila } \\
\text { Bali As Asri }\end{array}$ \\
General & $:$ Puncak pimpinan dari \\
Manager & sebuah struktur organisasi \\
& hotel, dan bertanggung jawab \\
Chief & terhadap operasional di Villa. \\
Security & security yang bertanggung \\
& jawab untuk menjaga \\
& keamanan internal dan \\
Room & eksternal bang bertanggung \\
Division & Divisi yang dalam pelayanan \\
Manager & kamar, terdiri dari \\
& Housekeeping dan Front \\
Accounting & Office. Divisi yang bertanggung \\
& jawab dalam pelayanan \\
& transaksi dan keuangan \\
\hline
\end{tabular}

\begin{tabular}{ll}
\hline Spa \& Gym & $\begin{array}{l}\text { : divisi yang bertanggung } \\
\text { jawab dalam pelayanan Spa } \\
\text { dan Gym } \\
\text { Security }\end{array}$ \\
$\begin{array}{l}\text { menjaga kertanggung jawab dalam } \\
\text { internal dan eksternal Villa di }\end{array}$ \\
Housekeeping & $\begin{array}{l}\text { : bertanggung jawab dalam } \\
\text { menjaga kebersihan sekitar }\end{array}$ \\
Gardening & $\begin{array}{l}\text { Villa, mempersiapkan kamar, } \\
\text { membersihkan kamar, serta } \\
\text { membersihkan public area, } \\
\text { serta gym dan spa. }\end{array}$ \\
\hline Sumber : Vila Bali Asri, 2018
\end{tabular}

Sumber : Vila Bali Asri, 2018

Hadi (2014) menyebutkan bahwa tugas utama Front Desk Agent adalah melayani segala kebutuhan administrasi dan informasi tamu hotel dari check in sampai dengan check out. Kemudian dengan meningkatnya tuntutan terhadap kepuasan pelayanan tamu, maka Front Desk Agent dituntut untuk memiliki performa lebih dalam memberikan pelayanan. Untuk menjadi seorang Front Desk Agent maka seseorang dituntut untuk mempunyai kemampuan dasar mulai dari menangani penerimaan tamu, pemesanan kamar, menerima dan membuat panggilan telepon, memeriksa tagihan tamu sampai membuat daily report.

\section{Guest Activity Cycle}

Semua tamu yang datang dan menginap di Vila mempunyai maksud dan tujuan tertentu. Dimana semua proses tersebut dapat disederhanakan dalam empat dasar kegiatan yang merupakan siklus dan perputaran kegiatan tamu selama menginap. Siklus dan perputaran Kegiatan Tamu dalam Vila Bali Asri antara lain : 
Tabel 2

Siklus Aktivitas Tamu dan Peran Front Desk Agent pada Vila Bali Asri Seminyak

\begin{tabular}{lll}
\hline No. & $\begin{array}{c}\text { Nama } \\
\text { Kegiatan }\end{array}$ & \multicolumn{2}{c}{ Jenis Kegiatan } \\
\hline 1. & Sebelum & Reservation \\
(pre- Arrival) & a) Tamu menentukan tipe kamar \\
& yang akan dipilih, dimana pilihan \\
& ini dipengaruhi oleh beberapa hal \\
& apakah sudah pernah tinggal \\
& disitu, mendengar cerita tentang \\
& Vilatersebut. \\
& b) Petugas Reservasi harus mampu \\
& menjawab secara cepat dan \\
& akurat akan kebutuhan tamu untuk \\
& resercasi dengan mengirimkan \\
& confirmation reservation letter \\
& (surat tanda persetujuan \\
& memperoleh kamar), jika tamu \\
& sudah menyatakan confirm untuk \\
& memperoleh kamar.
\end{tabular}

2. Kedatangan

Tamu

(Arrival)

3. Saat Tamu

Tinggal di

Hotel (During

the Stay)

4. Saat tamu meninggalkan

\section{Prosedur Check in}

a) Tamu datang dan menuju ke reception/registration desk untuk mendaftarkan diri.

b) Pihak receptionist akan menanyakan kepada tamu tentang reservasi atau belum.

1) Jika belum, maka akan dan

2) jika sudah, maka tamu akan diberikan registration Form

c) Tamu mengisi Registration Form Escort the guest to the room

Tamu memasuki kamar dengan dua cara, yaitu menuju kamar sendiri atau diantar oleh petugas (bellboy). Setelah sampai di Vila, maka tamu akan dijelaskan fasilitas yang ada di Vila hingga berbagai informasi terkait.

\section{Service the Guest}

Semua staff hotel berupaya untuk memberikan pelayanan tamu sesuai kebutuhan dan keinginan. Vila senantiasa berupaya agar tamu melaku kan pengeluaran (expenses) di Vilaselama tinggal, diantaranya laundry, room service, dinner, spa, gym, sewa motor, paket wisata, dan lain lain.

Peran Front Desk Agent dalam melayani tamu diantaranya adalah dengan memberikan informasi yang dibutuhkan, berkoordinasi dengan pihak terkait baik internal maupun eksternal Vila, mampu merekomendasikan paket wisata yang dibutuhkan, dan lain lain.

Prosedur Check out
1) Front Desk Agent akan
menyediakan Expected
diberikan Reservation form,
Hotel

(departure)
Departured List sehari sebelum tamu check out untuk memastikan bill yang ditagihkan dan mempersiapkan transportasi.

2) Front Desk Agent akan menghubungi bell boy untuk mengangkut barang- barang bawaan tamu.

3) Front Desk Agent bekerja sama dengan Accounting dalam menyiapkan guest bill yang perlu ditagihkan kepada tamu dan melakukan proses transaksi pembayaran.

4) Front Desk Agent meminta feedback dari tamu terkait tingkat kepuasan dalam menginap di Vila Bali Asri, dan mengucapkan salam perpisahan yang baik.

Sumber : diolah dari berbagai sumberdata, 2019

\section{Image Builder}

Citra merupakan kesan, perasaan gembira dari public terhadap perusahaan atau organisasi, kesan yang sengaja diciptakan dari suatu objek, orang, atau organisasi. Citra perusahaan yang baik merupakan sebuah asset bagi kebanyakan perusahaan (lembaga), karena citra perusahaan memiliki suatu dampak terhadap persepsi pelanggan/ masyarakat dari komunikasi dan operasional perusahaan yang sangat memperhatikan produknya. Sehingga citra perusahaan tidak bisa direkayasa karena citra positif akan terbentuk dengan sendirinya melalui kualitas dari lembaga atau perusahaan itu sendiri.

Menurut Bob Sabran (2009:607), Citra terdiri dari kepercayaan, ide, dan kesan yang dipegang oleh seseorang terhadap sebuah obyek. Sebagian besar sikap dan tindakan orang terhadap suatu objek dipengaruhi oleh citra suatu objek. Dimana citra dapat diukur (Aaker: 2006,22) melalui pendapat, kesan tanggapan seseorang dengan tujuan untuk mengetahui secara pasti apa yang ada pada setiap pikiran individu mengenai suatu objek, bagaimana mereka memahami dan apa yang mereka sukai dan tidak dari objek tersebut. Suatu 
citra terhadap objek bisa berlainan tergantung persepsi perorangan bahkan bisa saja citra satu objek sama bagi semua orang. Tujuan dari citra produk sendiri adalah untuk meningkatkan penjualan bagi perusahaan, salah satunya dengan cara mempertahankan citra mereka terhadap para pelanggan yang loyal terhadap perusahaan, kepuasan pelanggan terhadap produk perusahaan. Kepuasan tamu selama menginap di Vila Bali Asri dapat diamati dari hasil Guest Review dimana terdapat respon puas terhadap Pelayanan yang diberikan Front Desk Agent. Namun pihak Vila diharapkan dapat tetap memberikan training dan pelatihan pada Front Desk Agent untuk dapat menjaga konsistensi dalam pembentuk citra yang positif terhadap Vilatersebut.

Wachidyah (2017) menganalisa peranan Front Office Departemen sebagai First and Last Impression dalam memberikan layanan kepada tamu yang mengacu pada lima dimensi kualitas layanan yaitu

1) Reliability (keandalan), merupakan kemampuan perusahaan untuk memberikan pelayanan sesuai dengan yang dijanjikan secara akurat dan terpercaya.

2) Responsiveness (cepat tanggap), merupakan suatu kebijakan untuk membantu dan memberikan pelayanan yang cepat (responsive) dan tepat kepada pelanggan dengan penyampaian informasi yang jelas.

3) Asurance (jaminan), merupakan pengetahuan kesopansantunan, dan kemampuan para pegawai perusahaan untuk menumbuhkan rasa percaya para pelanggan kepada perusahaan.

4) empathy (empati), merupakan pemberian perhatian yang tulus dan bersifat individual atau pribadi yang diberikan kepada para pelanggan dengan berupaya memahami keinginan konsumen.

5) tangible (bukti langsung/berwujud), merupakan kemampuan suatu perusahaan dalam menunjukkan eksistensinya kepada pihak eksternal

\section{Reliability}

Front Desk Agent memiliki proses pelayanan reservasi kamar yang efektif dan efisien. Dalam pelayanan reservasinya, Vila Bali Asri mengelola reservasi online baik melalui website dan Travel Agent Online supaya dapat mengakomodasi keinginan calon tamu yang ingin tinggal di Vilai ni. Selain itu Front Desk Agent juga memastikan pelayanan check in dan check out dapat berjalan dengan tepat dan akurat.

\section{Responsiveness}

Sebagai agen pelayanan yang bekerja di sektor hospitality, maka Front Desk Agent diharapkan memiliki tingkat ketanggapan yang tinggi terhadap pelayanan kebutuhan dan keinginan tamu. Front Desk Agent pada Vila Bali Asri memiliki sistem jaminan terhadap setiap request order order tamu yang bernama "fifteen minutes guarantee service", artinya adalah terdapat jaminan pelayanan untuk menyelesaikan setiap keluhan tamu atau kebutuhan tamu maksimal berdurasi waktu 15 menit. Setiap keluhan dan kebutuhan tamu dicatat dalam Logbook untuk kemudian di-follow- up oleh beberapa pihak terkait. Log Book tersebut rutin dimonitoring dan dievaluasi oleh Front Office Supervisor untuk memastikan kecepatan daya tanggap Front Desk Agent dalam pelayanan keluhan tamu maupun kebutuhan serta keinginan tamu.

\section{Assurance}

Assurance merupakan pengetahuan kesopansantunan, dan kemampuan para pegawai perusahaan untuk menumbukan 
rasa percaya para pelanggan kepada perusahaan. Jaminan disini diartikan sebagai jaminan service dari Front Office yang diperoleh dari pengetahuan dan kemampuan karyawan terhadap deskripsi tugasnya sebagai Front Desk Agent. Vila Bali Asri memastikan bahwa setiap Front Desk Agentnya memahami pengetahuan kerja (Knowledge of Work) terhadap Standar Operational Proceddure (SOP) dari berbagai proses di Front Office Departemen seperti pelayanan check in, check out, handling guest complain, handling guest luggage supaya setiap pelayanan dapat berjalan secara efektik, efesien, dan terpadu. Selain itu Front Desk Agent di Vila Bali Asri dituntut untuk memahami product knowledge sehingga dapat memberikan informasi yang benar kepada tamu.

\section{Empathy}

Kepedulian dan perhatian Front Desk Agent di Vila Bali Asri secara personal kepada tamu terutama untuk memenuhi kebutuhan dari tamu. Contohnya secara personal, pihak Front Desk Agent akan mengkomunikasikan hari spesial tamu seperti memberikan surprise Cake pada tamu yang sedang berulang tahun. Selain itu, pihak Front Desk Agent secara aktif selalu menawarkan bantuan transportasi kepada tamu, atau merekomendasikan paket wisata atau tempat wisata kepada tamu yang baru pertama kali ke Bali. Empati itu pun pada akhirnya menciptakan hubungan dekat tamu dengan VilaBali Asri, sehingga tamu tersebut nyaman dan betah tinggal di Villa, dan menjadi repetear guest (tamu langganan) di Vilatersebut. Selain itu pula, Front Desk Agent juga berpertan aktif dalam mengirimkan birthday greating dan special occasion greating melalui email baik tamu yang pernah tinggal di Vila Bali Asri untuk menjaga hubungan baik dengan tamu.

\section{Tangible}

Penampilan fasilitas fisik, peralatan, karyawan, dan material yang terdapat di VilaBali Asri. Penataan dan kebersihan dari lobi dan public area merupakan sebuah keharusan, karena merupakan departemen yang selalu dikunjungi oleh para tamu, sehingga dapat memberikan kesan yang baik terhadap citra Villa. Sehingga Front Desk Agent berkoordinasi dengan Public Area untuk membersihkan lobi dan area sekitarnya setiap pagi dan sore. Selain itu, dalam operasionalnya sehari-hari pihak Front Desk Agent diharapkan dapat menjaga desknya agar rapi dan terorganisir, menghindari tumpukan kertas dan alat tulis yang berserakan, terkait pelayanannya dalam kebutuhan administrasi. Penampilan Front Desk Agent dituntut untuk selalu well grooming menggunakan seragam yang rapi dan harum, menggunakan name tag, bagi Front Desk Agent wanita agar selalu menggunakan harnet untuk menjaga rambutnya, dan tidak terlalu menggunakan perhiasan yang berlebihan.

\section{KESIMPULAN}

Hasil dan pembahasan menunjukkan bahwa Front Desk Agent sangat berperan pada pembentukan citra positif pada Vila Bali Asri terutama Sebagai first and last impression bagi tamu. Apabila kesan yang ditampilkan buruk, maka bersinergi dengan citra hotel, begitu juga sebaliknya. Sehingga Front Desk Agent harus memiliki keramahtamahan dan sikap siap membantu dan sopan. Selain itu, Front Desk Agent harus membina hubungan baik antar dan inter departemen dalam Vila secara internal, dan secara eksternal dengan membina hubungan baik dengan perusahaan yang bekerja sama dengan Vila Bali Asri diantaranya channel distribution (saluran distribusi penjualan) yaitu Biro Perjalalan Wisata (BPW) dan Online Travel Agent 
(OTA), competitor, serta terutama pada loyal customer.

\section{DAFTAR RUJUKAN}

Dewi, Herlina lka Ratna. (2011). Peran Public Relations dalam membangun Citra pada Hotel Bintang Mulia Jember. Skripsi. Program Studi IImu Administrasi Niaga Fakultas IImu Sosial dan IImu Politik Universitas Jember.

Hadi, Wisnu. (2014) Peranan Front Desk Agent dalam membentuk Citra Positif di Dunia Perhotelan. Jurnal Khasanah Ilmu Vol V No.2 September 2014, Yogyakarta.

Hartopo, Dian. (2011). Peranan Front Office Departemen dalam Memberikan Pelayanan kepada Pengujung di Hotel dan Pemandian Kebon Agung Jember. Laporan Praktek Kerja Nyata. Program Diploma DIII Pariwisata Jurusan IImu Administrasi Fakultas Sosial dan IImu Politik Universitas Jember.

Izzah, Lailatul. (2013). Peranan Departemen Front Office sebagai Kesan Pertama Penentu Citra bagi Tamu di Hotel Istana Kabupaten Jember. Laporan Praktek Kerja Nyata. Program Studi Diploma III Usaha Perjalanan Wisata Jurusan IImu Administrasi Fakultas IImu Sosial dan IImu Politik Universitas Jember.

Namira, Diandra Marsya. (2010). The important Roles and Activities of Front Office Departement at Sahid Jaya Hotel Solo. Skripsi. Fakultas Sastra Inggris. Universitas Sebelas Maret
Saleh, Akhmad Muwafik. (2010). Public Service Communication 2010. UMM Press Malang.

Sihite, Richard. (2000). Tourism Industry, Surabaya : SIC

Suarthana, I Ketut Putra. (1986). Front Office Hotel (Front Office). Badung: Manajemen Perhotelan Indonesia.

Sulastri, Nunik. (2009). Mekanisme Kerja Reception dalam Meningkatkan Pelayanan Tamu di The Sunan Hotel Solo (Studi dalam tahun 2005-2008). Laporan Tugas Akhir. Fakultas Sastra dan Seni Rupa Universitas Sebelas Maret Surakarta

Wardoyo, FX. Soejatno. (1985). Front Office Procedures. Surabaya.

Wachidyah, Wiwin. (2017). Front Office Departement dan Peranannya dalam Layanan Tamu Hotel. Jurnal Bisnis \& Teknologi Politeknik NSC Surabaya. ISSBN : 2355- 8865 \& E- ISSN : 2356- 2544. Volume 4, Nomor 1, Juli 2017 